\title{
Sero-prevalence of malaria, hepatitis $b$ and syphilis among pregnant women in Osogbo, Southwestern Nigeria
}

\author{
Adeleke, M. A. ${ }^{1 *}$, Adebimpe, W. O. ${ }^{2}$, Sam-Wobo, S. O. ${ }^{3}$, Wahab, A. A. ${ }^{1}$, Akinyosoye, L. S. ${ }^{1}$ and \\ Adelowo, T. O. ${ }^{1}$ \\ ${ }^{1}$ Department of Biological Sciences, Osun State University, P.M.B 4429, Osogbo, Nigeria. \\ ${ }^{2}$ Department of Community Medicine, College of Health Sciences, Osun State University, Osogbo, Nigeria. \\ ${ }^{3}$ Department of Biological Sciences, Federal University of Agriculture, Abeokuta, Nigeria.
}

Accepted 2 July, 2013

\begin{abstract}
Malaria, syphilis and Hepatitis B during pregnancy are detrimental to the life of the pregnant women and the foetus. In this study, we documented the prevalence of the three diseases among pregnant women attending a selected Comprehensive Health Care center in Osogbo, Nigeria using serological kits. Of the 200 participants consented to participate in the study, 26 (13\%) were positive for malaria while $6(3 \%)$ were positive for Hapatitis B Virus (HBV). The co-infection of malaria and HBV was found only in two participants (1\%) while none of the participants was positive for syphilis. There was no significant difference in the prevalence of malaria and Hepatitis $B$ in relation to age $(p>0.05)$. All the participants had good knowledge that mosquitoes transmit malaria but only $29(14.5 \%)$ claimed to be sleeping under insecticide treated bed-net. About $169(84.5 \%)$ relied solely on insecticide spray of the room and $2(1 \%)$ did not practice any mosquito control measures. The results may suggest the low prevalence of malaria, Hepatitis B virus and syphilis at the study area. However, early surveillance and adequate public health education will be immeasurable in safe-guiding the pregnant women from the detrimental effects of these infections.
\end{abstract}

Key words: Malaria, syphilis, hepatitis B virus, pregnant women, co-infection, Nigeria.

\section{INTRODUCTION}

Malaria is of considerable public health problem in Africa, with pregnant women and children under five bearing the major burden of the infection. In Nigeria, malaria has been known to account for $11.5 \%$ of maternal death (Agomo et al., 2009). Plasmodium falciparum, the predominant and most virulent malaria species in Nigeria has been identified as major cause of low birth weight, still births, spontaneous abortion or death of the susceptible pregnant women (Idowu et al., 2006). Syphilis is a sexually transmitted infection (STI) caused by the Treponema pallidum spirochete. T. pallidum subspecies pallidum is a gram-negative, very mobile bac- 
terium (Eccleston et al., 2008). Hepatitis B is an infectious inflammatory illness of the liver caused by the hepatitis B virus (HBV) that affects hominoidea, including humans. The virus is transmitted by exposure to infectious blood or body fluids such as semen and vaginal fluids (Stamm, 2010; Chang, 2007).

The complications of malaria, syphilis and hepatitis $B$ are more pronounced among immune-compromised patients such as pregnant women and HIV infected individuals. These three infectious diseases cause similar adverse pregnancy outcomes which include spontaneous abortion, still birth or death of the pregnant women (Shafer and Moscick, 2006; Olokoba et al., 2008). Therefore, early diagnosis of these deadly infections through screening among the pregnant women is crucial to the ongoing efforts and campaign on the reduction of maternal and child mortality in Nigeria. This study, thus presents the results of sero-prevalence of malaria, hepatitis $B$ virus and syphilis conducted among pregnant women attending selected primary health facilities in Osogbo, Southwest, Nigeria.

\section{MATERIALS AND METHODS}

\section{Study area}

The study was conducted in Osogbo, the capital of Osun State in Southwestern Nigeria. It lies on the latitude $7^{\circ} 46 \mathrm{~N}$ and Longitude $4^{\circ} 36 \mathrm{E}$, and has a population of 156,694 .

\section{Study design}

This is a descriptive cross sectional study carried out among the pregnant women attending antenatal session at Ita-Akogun Health Care center in Osogbo, Southwestern Nigeria. All pregnant women who consented to the screening after counseling session carried out by the nurse counselor were enrolled for the study.

\section{Ethical clearance}

Ethical clearance was obtained from the research ethics committee of Osun State University College of Health Sciences. Permission was sought from the Management of the Clinic and informed consent was also sought and obtained from the participants.

\section{Data collection}

Semi structured and pre tested questionnaires were administered to the participants by the researchers to obtain information on the age, occupation, and knowledge on the diseases under study. After the questionnaire administration, sterile disposable syringes were used to collect blood (about $5 \mathrm{ml}$ ) from the veno-punctured vein under aseptic conditions. All the specimens were tested for malaria, syphilis and hepatitis B using rapid serological kits for syphilis, malaria and HBV (Global, Germany), according to manufacturer's instructions. The study was conducted between November, 2011 and February, 2012.

\section{Data analysis}

Data was validated through double entry and random checks and analyzed using statistical package for social sciences (SPSS) software (version 17.0) and frequency tables generated. The chisquare test was used to determine association between categorical variables and significant difference in the parameters determine at $\mathrm{P}<0.05$.

\section{RESULTS}

A total of 200 participants consented to be enrolled for the study within the study period. The demographic data of the study participants are presented in Table 1. Most of the study participants were within the age group of 25 to 30 years $(40 \%)$ followed by 20 to 25 years $(32.5 \%)$, while age group above 35 constituted the least $(2.5 \%)$. Majority of participants were traders (39\%) with no formal education (74.5\%). None of the 200 participants screened was positive for syphilis. However, $26(13 \%)$ were positive for malaria while $6(3 \%)$ were positive for HBV. The co-infection of malaria and hepatitis was found only in two participants $(1 \%)$ as seen in Table 2 . There was no significant difference in the prevalence of malaria and hepatitis $B$ in relation to age $(p>0.05)$ as seen in Table 3. The questionnaire survey showed that only little proportion of the study participants (5\%) previously had sexually transmitted infections (STIs). Most of the participants have never had blood transfusion (99\%). All the participants had good knowledge that mosquito transmit malaria but only $29(14.5 \%)$ usually claimed to be sleeping under insecticide treated bed net while 169 $(84.5 \%)$ relied only on insecticide spray of the room, and $2(1 \%)$ did not practice any mosquito control measures as in Table 4.

\section{DISCUSSION}

The results of the present study showed that the prevalence of malaria in pregnancy is higher than hepatitis B while co-infection is extremely low. A prevalence of $13 \%$ of malaria was recorded which, albeit, extremely low when compared with high prevalence (72\%) earlier reported by Adefioye et al. (2007), for malaria in pregnancy in Osogbo, Nigeria. The difference in the prevalent rate could be associated with many factors among which are diagnostic tool used, period of the study, environmental conditions, improved malaria control activities, and over-diagnosis. Though, only few participants claimed to be sleeping under ITN as revealed by questionnaire survey. 
Table 1. Demographical data of the pregnant women.

\begin{tabular}{lcc}
\hline Demographic information & Frequency & Percentage \\
\hline Age & & \\
$15-20$ & 10 & 5 \\
$21-25$ & 65 & 32.5 \\
$26-30$ & 80 & 40 \\
$31-35$ & 40 & 20 \\
Above 35 & 5 & 2.5 \\
& & \\
Occupation & & \\
Trading & 78 & 39 \\
Civil servants & 52 & 26 \\
Health workers & 33 & 16.5 \\
Others & 37 & 18.5 \\
& & \\
Educational status & & \\
Formal education & 51 & 25.5 \\
Informal education & 159 & 74.5 \\
\hline
\end{tabular}

Table 2. Prevalence of malaria, syphilis and hepatitis B among the pregnant women.

\begin{tabular}{lcccccc}
\hline Parameter & Syphilis & Malaria & Hepatitis B & $\begin{array}{c}\text { Malaria and } \\
\text { hepatitis B }\end{array}$ & Malaria and syphilis & $\begin{array}{c}\text { Syphilis and } \\
\text { hepatitis B }\end{array}$ \\
\hline No positive (\%) & $0(0)$ & $26(13)$ & $6(3)$ & $2(1)$ & $0(0)$ & $0(0)$ \\
No negative (\%) & $200(100)$ & $174(87)$ & $194(97)$ & $198(99)$ & $200(100)$ & $200(100)$ \\
\hline
\end{tabular}

Table 3. Prevalence of malaria and hepatitis B in relation to age among pregnant women.

\begin{tabular}{cccc}
\hline Age group & No screened & No positive for malaria (\%) & No positive for hepatitis B (\%) \\
\hline $15-20$ & 10 & $1(10)$ & $1(10)$ \\
$21-25$ & 65 & $5(7.7)$ & $3(4.6)$ \\
$26-30$ & 80 & $16(20)$ & $2(2.5)$ \\
$31-35$ & 40 & $4(10)$ & $0(0)$ \\
36 and above & 5 & $0(0)$ & $0(0)$ \\
\hline
\end{tabular}

Osogbo metropolis has witnessed tremendous improvement in environmental sanitation in the past one year due to the weekly environmental sanitation exercise declared by Osun State Government. This activity could have led to the elimination of potential breeding sites of malaria vectors. This observation, coupled with the fact that the present study was conducted in the dry season could have culminated in the low prevalence of malaria recorded. Moreover, unlike previous study which used microscopic technique, the present work utilized rapid diagnostic kit which is specific for detection of $P$. faciparium only. Recent studies in Nigeria and other African countries have shown that the high prevalence of malaria reported in some endemic communities using microscopy may be in part, due to over-diagnosis (Agomo et al., 2009; Zurovac et al., 2006). If these observations are sustained, there is need for re-validation of the existing data on malaria in Nigeria, most importantly in areas where high prevalence has been previously reported.

Though, the prevalence of hepatitis $B$ and its coinfection with malaria was low in this study, the co-infection 
Table 4. Knowledge on STD, sexual activity and malaria prevention among the pregnant women.

\begin{tabular}{lcc}
\hline Parameter & Frequency & Percentage \\
\hline Knowledge on STI & 10 & 5 \\
Yes & 190 & 95 \\
No & & \\
& & \\
Sexual activity & 200 & 100 \\
One sexual partner & 0 & 0 \\
More than one & & \\
& 200 & 100 \\
Knowledge on malaria transmission & 0 & 0 \\
Yes & & \\
No & 169 & 84.5 \\
& 29 & 14.5 \\
Malaria prevention & 2 & 1 \\
Insecticide spray & & \\
ITN usage & \\
None & & \\
\hline
\end{tabular}

of both infectious diseases is detrimental to the life of pregnant women and the un-born baby. Almost $90 \%$ of babies delivered with mothers having HVB will become chronically infected with hepatitis $B$ at birth if there is no prevention (Stamm, 2010; Chang, 2007). The usual clinical signs are jaundice, hepatic tenderness, and weight loss (Chang, 2007). The figure obtained from the current study was lower than the previous data on HBV $(18.6 \%)$ among the pregnant women in a tertiary Institution in Osogbo (Kolawole et al., 2012). This may be due to the difference in diversity of patients attending the tertiary institution as compared to a local comprehensive health centre that is mainly patronized by the people within the community.

According to the Federal Ministry of Health (FMOH), the national prevalence for syphilis among Nigerian pregnant women was estimated as $0.3 \%(\mathrm{FMOH}, 2004)$. The zero prevalence of syphilis recorded in the present study may indicate extremely low cases of the infection at the study area. Previous studies in different parts of Nigeria have also reported low prevalence (Ozumba et al., 1999; Aboyeji and Nwabuisi, 2003), far less than reported prevalence in some African Countries such as Zambia (12.5\%) (Ratnam et al., 1982), Mozambique (18.3\%) (Lindstrand et al., 1993), and Malawi (5\%) (Kwiek et al., 2008). It is however, not illogical to express that congenital syphilis may not be a major cause of perinatal mortality in the study area.

\section{CONCLUSION}

The results of the study demonstrated the low prevalence of malaria, hepatitis B and syphilis at the study area. Though routine screening for co-infections are rare practices, authors advocates regular surveillance and adequate public health education targeted at these diseases, as it is valuable in safe-guiding these immunecompromised women from the detrimental effects of these infections.

\section{ACKNOWLEDGEMENTS}

Sincere appreciation to the ethical review committee of UNIOSUN, the heads of selected health facilities and the pregnant women who consented to taking part in study.

\section{REFERENCES}

Aboyeji AP, Nwabuisi C (2003). Prevalence of sexually transmitted diseases among pregnant women in Ilorin, Nigeria. J. Obstet. Gynaecol. 23(6):637-639.

Adefioye OA, Adeyeba OA, Hassan WO, Oyeniran OA (2007). Prevalence of malaria parasite infection among pregnant women in Osogbo, Southwest Nigeria. Am. Eurasian J. Sci. Res. 2(1):43-45.

Agomo CO, Oyibo WA, Anorlu RI, Agomo PU (2009). Prevalence of malaria in pregnant women in Lagos, Southwestern Nigeria. Korean J. Parasitol. 47(2):179-183.

Chang M (2007). Hepatitis B virus infection. Seminars in fetal and neonatal medicine 12(3):160-167.

Eccleston K, Collins L, Higgins SP (2008). Primary syphilis. Int. J. STD AIDS. 19(3):145-51.

Federal Ministry of Health (2004). Technical report on 2003 National HIV/Syphilis sentinel survey among pregnant women attending antenatal clinics in Nigeria, Abuja. Nigeria. Federal Ministry of Health p 125.

Idowu OA, Mafiana CF, Sotiloye S (2006). Malaria among pregnant 
women in Abeokuta, Nigeria. Tanzan. Health Res. Bull. 8(1):28-31. Kolawole OM, Wahab AA, Adekanle DA, Sibanda TS, Okoh AI (2012). Seroprevalence of Hepatitis B surface antigenemia and its effects on haematological parameters in Pregnant women in Osogbo, Nigeria Virol. J. 9:317-321.

Kwiek JJ, Mwapasa V, Alker AP, Muula AS, Misiri HE, Molyneux ME (2008). Socio-demographic characteristics associated with HIV and Syphilis seroreactivity among pregnant women in Blantyre, Malawi, 2000-2004. Malawi Med. J. 20(3):80-85.

Lindstrand A, Bergstrom S, Bugalho A, Zanconato G, Helgesson AM, Hederstedt B (1993). Prevalence of Syphilis infection in Mozambican women with second trimester miscarriage and women attending antenatal care in second trimester. Genitourin Med. 69(6):421-433.

Olokoba AB, Olokoba IB, Salawu FK, Danburam A, Desalu OO, Midala JK (2008). Syphilis and HIV co-infection in North-eastern Nigeria. Int. J. Trop. Med. 3(3):70-72.

Ozumba UC, Oshi DC, Nwokeji CM, Anya SE (1999). Trends in seroreactivity of syphilis among pregnant Nigerian women. Sex. Transm. Infect. 75:120-123.
Ratnam AV, Din SN, Hira SK, Bhat GJ, Wacha DS, Rukmini A (1982). Syphilis in pregnant women in Zambia. Br. J. Vener. Dis. 58(6):355358.

Shafer M, Moscicki A (2006). Sexually Transmitted Infections. 1 - 8. (Website: www.biomedexperts.com/Profile.bme/...Mary-Ann Shafer).

Stamm LV (2010). "Global challenge of antibiotic-resistant Treponema pallidum". Antimicrob. Agents Chemother. 54(2):583-589.

Zurovac D, Midia B, Ochola SA, English M, Snow RW (2006). Microscopy and outpatient malaria case management among older children and adults in Kenya. Trop. Med. Int. Health 11:432-440. 